\title{
A Contrastive Study of Disciplinary Identity in English Research Articles by Advanced Learners and Experts*
}

\author{
Liang Chu \\ School of Foreign Studies \\ Xi'an University \\ Xi'an China
}

\author{
Zhuo Ben \\ School of Foreign Studies \\ Xi'an University \\ Xi'an China
}

\begin{abstract}
EAP writing is a kind of academic interaction and communication between author and reader. In addition to presenting his own views, the author uses a series of means to interact with the reader to build his own identity. In recent years, identity construction has become a hot topic in EAP writing. However, there are few researches on the identity construction of academic thesis writing. So far, there has been a few research on the writing of foreign languages other than English Majors. This paper uses AntConc software to search for personal pronouns in a self-built Corpus (mechanical engineering and Energy Engineering).Data were collected and analyzed by excel and text editor, so as to discover the similarities and differences in the use of personal pronouns between L2 and L1 EAP writing. It is found that there is a great difference in the construction of identity between the two group: (1) Native speakers use first person pronouns more often in their writing, while preferring the singular use of first person pronouns, but Chinese L2 are more likely to use the plural form. (2) Native language experts do not use the third person to construct their identity, while L2 learners tended to do so. This is possibly caused by:(1) different model of thinking (2) various English competence (3) diverse academic teaching tradition.
\end{abstract}

Keywords-academic writing; identity construction; personal pronoun

\section{INTRODUCTION}

The purpose of the academic paper is to explain the research content objectively and neutrally, and to convey the information as the main purpose, without adulterating the author' s personal feelings and attitudes. But in practice, the authors of academic papers should not only present,but also evaluate the findings.(Hyland \& Tse.2005;39) By comparing its value with the research of other scholars, it persuades the reader to accept his or her views.Ken Hyland believes that the author construct his identity can not only increase his credibility,but also take responsibility for the ideas he proposes.So it is very important for academic writing to construct the identity appropriately.but it is not easy for non native speakers. Since they find it difficult to give evaluative

*This work was supported by a grant from the Education Department of ShaanXi Provincial Government (NO. 17JK1108). opinions and attitudes to others and their findings as appropriate on the basis of academic papers, nor are they aware of the importance and necessity of doing so, it is therefore difficult to pronounce your "voice" accurately in academic papers.There are a lot of studies have found that the inadequate and inappropriate identity construction had become one of the major obstacles to the admission of academic papers by non-native language writers. Therefore, it is important to deeply analyze the different ways of identity construction between the Chinese L2 Learners and the author of the native language.

Taking these into consideration, I conducted this research focused on above-mentioned linguistic phenomenon from the perspective of corpora linguistics. This study will use academic papers written by Chinese learners and natives experts majored in Energy Engineering and Power Engineering as the linguistic data. The result can reflect how identity is constructed through the use of personal pronoun. After comparing the data between the four corpora, we can find out the pronoun frequency differences between four corpora, and the possible reasons led to the differences is discussed. It is hoped that findings of this research could provide some pedagogical implication for EAP writing.

\section{LITERATURE REVIEW}

\section{A. Historical Development of Academic Writing}

Since the movement of "cross-curricular writing" and "discipline writing" in the western countries in the 1980s, academic writing has attracted the attention of the educational circles. So, there are lots of learners proposed a great deal of articles. The early research on second language academic writing was based on the theory of one-language and two-language writing, and it was not until the middle and late 20th century that people began to put forward the theoretical conception of academic writing (Paltridge et $\mathrm{Al}$ 2009; Murray et Al 2006). Paltridge and others put forward a model of second language academic writing based on the cognitive, social and stylistic perspectives of the cognitive writing model and the written language output model. Later, the research field was extended to the academic environment readers' consciousness, discipline characteristics and 
expectations. As John (1993) studied the interaction between reader consciousness, purpose of writing and text, Wong (2005) examined the impact of readers' awareness and writing purposes on the writing process.It has been a long history for researching the academic writing text. The early text description focuses on the structural analysis, such as the analysis of academic language in the 1960s, the study of the organizational model of academic texts after the 1970s, and the genre analysis that prevailed in the 1980s and 1990s. With the development of modern technology, Corpus method has been widely used in recent years.

The research of writing text is mainly focused on the features of language and the distribution of meta-discourse features, such as hedges and transitional languages (Hyland 2002), comparative analysis of the use of indicators and influencing factors in English Research articles (Hyland 2002a). Most of these studies use comparative analysis to find the lexical, syntactic and textual characteristics of different academic texts and their influencing factors. The purpose of these studies is to explore the shortcomings of L2 learners. In addition, the relationship between academic writing and identity construction has attracted more attention in recent years. Many studies have attempted to confirm the function of writing identity. The researchers also observe and study the tendency of second language learners to construct their authorship, such as Carla (2011), who found that the second language authors used fewer first-person pronouns, even if they were used only to illustrate a purpose or to interpret an analytic process, rather than being used to establish an opinion or to perform other functions. Tas (2008) noted that even $\mathrm{PhD}$-level writers try to avoid using the first person, or simply to "guide the reader" and "describe the research process and methods of research". This phenomenon is thought to be related to factors such as the genre and cultural background (such as Hyland 2004; Tang et Al 1999). Therefore, it is more challenging for a second language learner to learn the language characteristics of a scholarly text.

\section{B. Identity}

1) Identity construction: Identity Research first appeared in sociology, Bucholtz \& Hall (2005) based on the theory and practice of numerous discourse and identity studies, define identity as demographics, which encompass the macro-level such as class, gender, occupation, educational background etc, as well as temporary and specific interpersonal and participatory roles. In this definition,the temporary specific position is closely related to the identity construction.

Li Chengtuan (2010) believes that identity construction is a kind of language means (mainly instructions) which the speakers chosen in the communication, and it's also a kind of speech act to present the stance. Yuan Zhoumin (2009) believes that identity building is what normal people do to show and maintain an individual's ownership of people like him. Colloquially, it is the individual's ability to express his or her unique self to others through the relevant behavior or language in order to build its identity. Combined with the two definitions, this paper argues that identity construction is a way for the speaker to choose and use language resources to show his unique self in order to realize a communicative need.

2) Disciplinary identity: Disciplinary is a unique academic culture,with unique discourse norms and practics, which restrict the content and expression from the field, tenor and mode of discourse (Hyland, 2012). Therefore, in the course of English academic writing in the interdisciplinary background, the author will adopt different language resources to meet the discourse norms and practices of different disciplines, in order to win the "Disciplinary identity" (Hyland, 2012) of "qualified insiders' 'identity" in a particular field. Hyland (2012) believed that the construction of disciplinary identity is a process in which people demonstrate themselves in the interaction of the community routinely and repeatedly and use the language resources recognized and shared by members, and display their academic abilities.

In the field of academic discourse research, this problem has been paid much attention, and many researches have been done on the author's identity and its construction in the academic discourse. Within this realm, Most students focused on the discourse strategy of the author's identity construction, the academic community generally holds the view of "academic discourse writers negotiating their identity through various discourse strategies in the academic community" (Ivanic 1998; 329). Most studies have focused on first person pronouns, which suggest that first person pronouns are explicit markers of authorship, rhetorical functions that build the identity of authors, such as, Kuo (1999) has found that the high frequency use of first-person pronouns in scientific papers reflects the efforts of the author to build his identity and to develop a good interaction with the reader; The research of Tang \& John (1999) proves that the first-person pronoun has the function of constructing many kinds of authorship. By comparing the use of firstperson pronouns in Hyland (2002), it is found that the frequency of first-person pronoun in L2 learners is low, the author's identity is not obvious; Harwood (2005) analyzed the use of first-person pronouns in scientific papers in different disciplines and found that the writer use personal pronouns for self-identification and self-promotion even if in the natural science papers. Huang Daogang et Al. (2008) studied the use of first-person pronouns in the introduction of Chinese and foreign scientists' materials science, and found the difference between Chinese and foreign writers in their own existence and their own identity; Gao Xia (2015) compared the first-person use of academic papers by Chinese and foreign scientists, and found that scientific factors have a greater influence on the subjectivity of the writers than native language factor; Wu Chunxiao (2015) also study from the first person to construct the identity from different parts of the paper. In addition to the study of first person pronouns as a language resource of identity construction, scholars have recently attempted to explore the identity building function of other language resources in the academic discourse, such as self-proclaimed (Liu Shufen 2011; Wu Geqi 2013), Lexical bundles (Xu Fang 2011), etc. All of these studies 
have raised awareness of the problem of disciplinary identity in EAP writing. And they have begun to look at how more and more language resources help authors build identities and interact with readers.

\section{Corpus Linguistic and EAP Writing}

Learner corpus is a learner language database, also known as the machine reader corpus, which is established by collecting the natural languages of language learners in various written and spoken languages. With the rapid development of computer technology, since the 1990s, the corpus of foreign language learners has been established. These machine-readable learner corpora are divided into two main categories: especially large publishing companies develop commercial learner corpus for dictionary and textbook development. The number and size of the corpus of the academic learner vary, such as the 300 million-word international learner corpus, the 100,000-word Leuven international Speech corpus and the 100,000-word Mont Clare language database.In addition, there are small libraries developed by researchers and teachers in various countries. The development of corpus technology has made it possible to quantify a large number of learners' corpus, and, as Leech points out, the emergence of a learner corpus opens up new avenues for Second-language acquisition research in development, more objective and informative data as well as the means and methods of empirical research are provided. The collection of learner corpus is mainly used for EAP writing. The most commonly used method is the Contrastive Interlanguage Analysis (short for CIA). This method is first proposed for Granger (1996), which mainly compares the learner corpus with the native corpus to find out the difference between the two. This paper makes a corresponding research and analysis on EAP writing using this method.

In view of the above research background, the process of EAP writing is a process of Entering the discipline community. So, it is of great significance whether the construction of author's identity is successful or not. Research in related fields, although it has attracted the attention from some researchers (such as Hyland, 2002; Ouyang Huhua Tang Shiyi, 2006; Xu Fang, 2011; Wu Geqi, 2013) , the disciplinary identity construction in specific subjects still need to be studied in depth. This paper will use the CIA method to analyze the differences in the construction of author's identity in both native experts and Chinese L2 learners, thus providing a useful inspiration for EAP writing.In order to realize the aforementioned goals, this paper is attempting the following questions:

1.What is the frequency of use of personal pronoun in corpus?

2.What similarities and differences are shown in the construction of authorial identity between different groups of writers?
3.What are the influencing factors of the differences in disciplinary identity between different groups of writers?

\section{METHODOLOGY}

\section{A. Instrument}

In this paper, this paper used the AntConc3.2.0 and Text Editor and self-compiled corpus . AntConc is a freeware corpus analysis toolkit for concordancing and text analysis, which is University. Text editor is a useful tool to edit texts. AntConc contain eight tools: Concordance; Concordance Plot; File View; Clusters; N-Grams; Collocates; WordList and Keyword Lists. The author only used the following two tools: Concordance and Concordance Plot.

\section{B. Data Collection}

The corpus of this study was used to select native language writers and Chinese authors in the field of Energy Engineering and Mechanical Engineering. There are 22 journal articles in the academic corpus of the native language of the Engineering Energy major, which are selected from the paper of foreign English periodicals (EEA). There are 31 papers in the Chinese academic English corpus, which are selected from English journal papers published in China (ECA). The detailed information is shown in "Table I".

TABLE I. ARRANGEMENT OF THE CORPUS For ENERGY ENGINEERING

\begin{tabular}{|l|l|l|}
\hline Corpus & EEA & ECA \\
\hline Discipline & Energy Engineering & Energy Engineering \\
\hline Texts & 22 & 31 \\
\hline Running words & 630211 & 602861 \\
\hline
\end{tabular}

There are 44 journal articles in academic corpus of native language of the Mechanical Engineering major, which are selected from the paper oof foreign English periodicals (MEA). There are 46 papers in the Chinese academic English corpus, which are selected from English journal papers published in China (MCA). The detailed information is shown in Table II.

TABLE II. ARRANGEMENT OF THE CORPUS For MECHANICAL ENGINEERING

\begin{tabular}{|l|l|l|}
\hline Corpus & MEA & MCA \\
\hline Discipline & Mechanical Engineering & Mechanical Engineering \\
\hline Texts & 44 & 46 \\
\hline Running words & 1531372 & 1348663 \\
\hline
\end{tabular}

\section{Data Analysis}

The self-mention to be limited to the first personal pronouns and the third person nouns (the second person pronouns and the third person pronouns do not appear in the corpus). The first person includes personal pronouns "I","me","we", "us"; there are no possessive pronouns such as my,our,mine,ours and reflexive pronouns in the corpus. And the third person nouns include "the author", "the study", "the paper". 


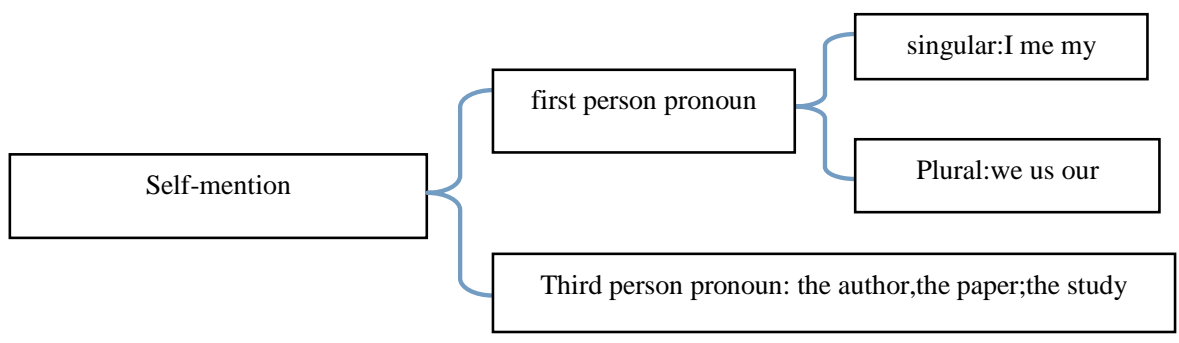

Fig. 1. Self-mention.

Then, statistic the frequency of above pronouns in the corpus. In order to analysis the data clearly, the author make the tables and charts to present the overall frequency and normalization(per 10000) of self-mention in the four corpus. The specific data is shown by the following charts and tables.

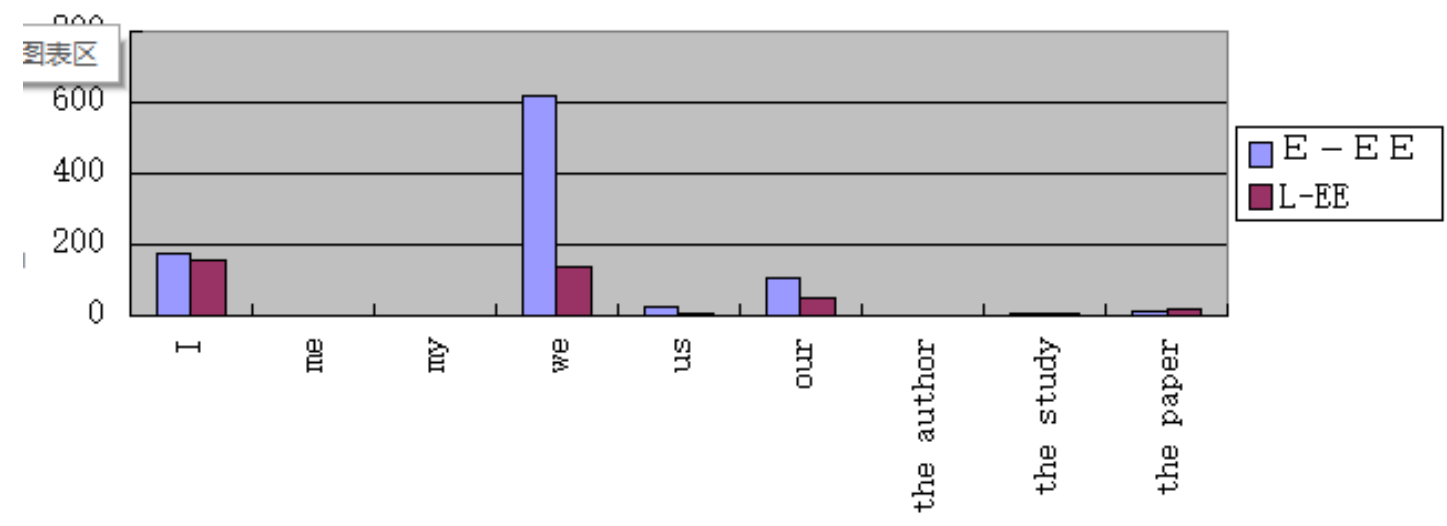

Fig. 2. The raw frequency of self-mention in the corpus of energy engineering major.

a. The column chart shows the raw frequency firstly, and then the normalization of the each form was calculated by the writer.

TABLE III. THE OVERALL FREQUENCY AND NORMALIZATION(PER 10000) OF SELF-MENTION IN THE CORPUS OF ENERGY ENGINEERING MAJOR

\begin{tabular}{|l|l|l|l|}
\hline & $\begin{array}{l}\text { Native } \\
\text { Experts }\end{array}$ & Frequency & $\begin{array}{l}\text { Normalizat } \\
\text { ion }\end{array}$ \\
\hline \multirow{4}{*}{$\begin{array}{l}\text { First } \\
\text { person } \\
\text { pronoun }\end{array}$} & I & 171 & 2.7134 \\
\cline { 2 - 4 } & me & 0 & 0 \\
\cline { 2 - 4 } & my & 0 & 0 \\
\cline { 2 - 4 } & we & 138 & 9.3830 \\
\cline { 2 - 4 } & us & 5 & 0.3491 \\
\cline { 2 - 4 } & our & 45 & 1.6661 \\
\hline & Total & 359 & \\
\hline \multirow{3}{*}{$\begin{array}{l}\text { Third } \\
\text { person } \\
\text { nouns }\end{array}$} & the author & 0 & 0.1959 \\
\cline { 2 - 4 } & the study & 3 & 0.1502 \\
\cline { 2 - 4 } & the paper & 8 & 0.1269 \\
\hline & Total & 11 & \\
\hline
\end{tabular}

From the "Table III", which could be found that the number of first person pronoun including singular and plural are used a lot than the third person nouns in the EEA corpus according the data 356 and 11.The case of the singular form and plural form is about the same according the data 171 and data 188. In the ECA corpus, the number of the first person pronoun including the singular and plural are used a lot than

\begin{tabular}{|l|l|l|l|}
\hline $\begin{array}{l}\text { Chinese } \\
\text { L2 }\end{array}$ & Frequency & $\begin{array}{l}\text { Normalizat } \\
\text { ion }\end{array}$ & Total \\
\hline I & 153 & 2.5379 & 324 \\
\hline me & 0 & 0 & 0 \\
\hline my & 0 & 0 & 0 \\
\hline we & & & 758 \\
\hline us & 620 & 2.2891 & 27 \\
\hline our & 22 & 0.0829 & 150 \\
\hline Total & 105 & 0.7464 & 1259 \\
\hline the author & 900 & & 0 \\
\hline the study & 0 & 0 & 5 \\
\hline the paper & 2 & 0.0332 & 24 \\
\hline Total & 16 & 0.2654 & 29 \\
\hline
\end{tabular}

the third person nouns according the data 900 and 18. It is obvious to see that the plural form occur 900 cases while the singular form occur 18 cases. Moreover, from the data we mention that the number of first singular form "I" (153 cases) and its plural form "we" (620 cases) are higher than the other items. 


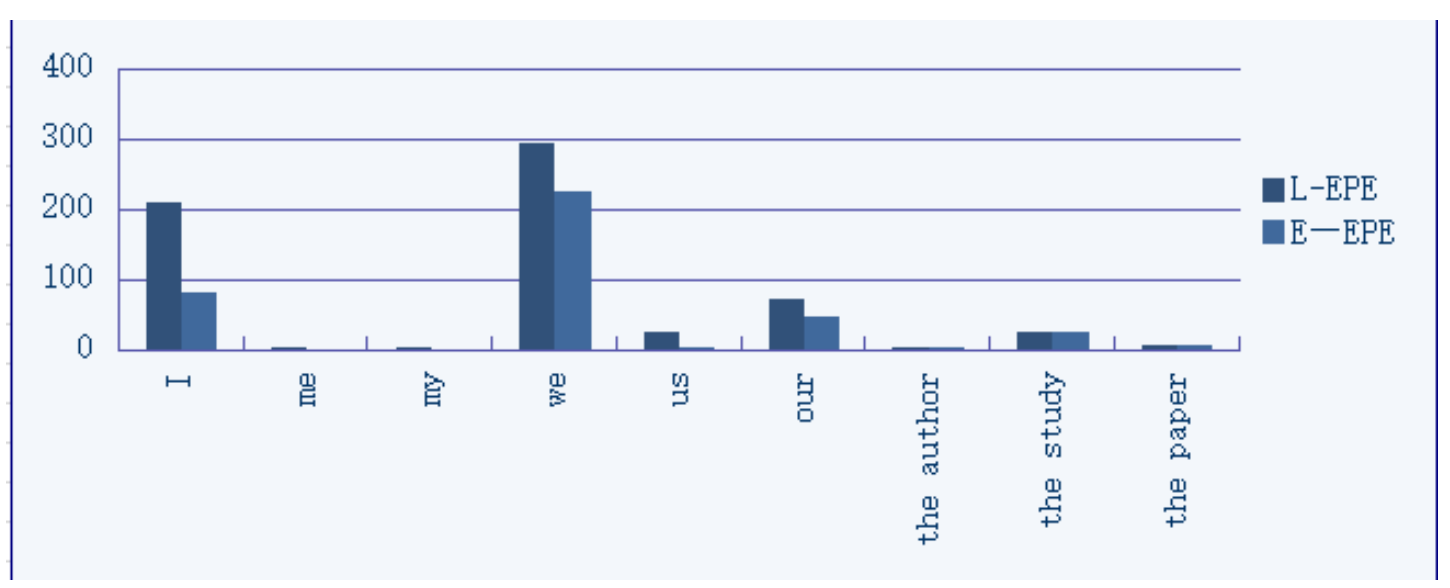

Fig. 3. The raw frequency of self-mention in the corpus of mechanical engineering major.

The column chart shows the raw frequency firstly, and then the normalization of the each form was calculated by the writer.

TABle IV. The Overall Frequency and Normalization (PER 10000) OF Personal Pronoun in Corpus of Mechanical Engineering Major

\begin{tabular}{|c|c|c|c|c|c|c|c|}
\hline & $\begin{array}{l}\text { Native } \\
\text { Experts }\end{array}$ & Frequency & Normalization & $\begin{array}{l}\text { Chinese } \\
\text { L2 }\end{array}$ & Frequency & $\begin{array}{l}\text { Normalizat } \\
\text { ion }\end{array}$ & Total \\
\hline \multirow{7}{*}{$\begin{array}{l}\text { First } \\
\text { person } \\
\text { pronoun }\end{array}$} & I & 208 & 1.3583 & I & 179 & 1.3272 & 387 \\
\hline & me & 3 & 0.0196 & me & 0 & 0 & 3 \\
\hline & my & 1 & 0.0065 & my & 0 & 0 & 1 \\
\hline & we & 223 & 1.9068 & we & 292 & 0 & 515 \\
\hline & us & 3 & 0.1567 & us & 24 & 1.6535 & 27 \\
\hline & our & 46 & 0.4636 & our & 71 & 0.3411 & 117 \\
\hline & Total & 484 & & Total & 566 & & \\
\hline \multirow{4}{*}{$\begin{array}{l}\text { Third } \\
\text { person } \\
\text { nouns } \\
\end{array}$} & the author & 3 & 0.0196 & the author & 2 & 0.0148 & 5 \\
\hline & the study & 23 & 0.1502 & the study & 24 & 0.1780 & 47 \\
\hline & The paper & 6 & 0.0392 & The paper & 4 & 0.0297 & 10 \\
\hline & Total & 32 & & Total & 30 & & \\
\hline
\end{tabular}

From the "Table IV", which could be found that the number of first person pronoun including singular and plural are used a lot than the third person nouns in the MEA corpus according the data 484 and 32 . The case of the singular form and plural form is about the same according the data 212 and data 272. In the MCA corpus, the number of the first person pronoun including the singular and plural are used a lot than the third person nouns according the data 566 and 30. It is obvious to see that the plural form occur 387cases while the singular form occur 179 cases. Moreover, from the data we mention that the number of first singular form "I" (179 cases) and its plural form "we" (292 cases) are higher than the other items.

\section{RESULT}

As we mentioned above, according to the frequency of First Person Pronouns and third person nouns, it is obviously find that Chinese L2 learners and native language experts are more likely to use the first person to express their views in academic papers. But there is a big difference in first-person pronoun use: Chinese L2 learners tend to use first-person plural forms such as "we" to construct their own identities, while native language experts are more likely to use the firstperson singular forms to express their views to build their own identities. The use of singular pronouns is intended primarily to highlight the indispensable role of researchers in the research process, while the use of plural pronouns is a sign of respect for the collective power of the academic community.

\section{DISCUSSION}

Based on the result mentioned above, the author offer some possible causes of differences in disciplinary identity between two group of people.

\section{A. Different Model of Thinking}

Influenced by the traditional Confucian culture, people have formed normative consciousness, group consciousness, form the same value orientation, personality standard and behavior pattern. Under this kind of atmosphere, the way of thinking tends to beg for the same difference, for the same difference or for the same, rather than the western standard of novelty, differentiation or the existence of differences.

But influenced by the atmosphere of democracy and science,the divergent model of thinking adopted by westerners form a sense of individuality, which courage people to explore, to express their views. Consequently, the Chinese are more inclined to use the first-person plural to express humility and avoid responsibility, while western 
individualistic thinking makes them more willing to use the first person singular to express their views and sell themselves.

\section{B. Various English Competence}

English is the first language of the Native speakers, hence their discourse competence is more higher than Chinese L2 learners ,they are also more familiar with the use of English. Chinese L2 learners will be affected by the transfer of the first language,they can't express themselves confidently. Native speakers are not afraid to make mistakes, and less uncertainty and doubt in their writing. This is why they are more confident in their role as authors and assume the responsibility of the author.

\section{Diverse Tradition of EAP Writing}

Because of the different teaching of EAP writing in China and the West, Chinese stylistics is more inclined to instruct students to avoid the use of singular personal pronouns in academic papers so as to achieve complete objectivity. In addition, it is feasible to construct the author's identity that the pronoun can appear in the writing of the thesis.

\section{PEDAGOGICAL IMPLICATION}

At present, the research on the function of the first-person pronoun needs to be improved, especially in light of the existing problems in the writing of academic papers in China. The following suggestions and strategies are put forward in this paper:

Chinese L2 learners should have a correct view of the academic tradition in China. The native experts have a high degree of personal participation, and they tend to articulate the author's identity in the discourse, taking responsibility for the findings and opinions, and differentiating their work from others. Chinese L2 learners, by contrast, prefer to avoid highlighting the way in which the author's identity is expressed, and fewer first person pronouns. This phenomenon is mainly influenced by the traditional Chinese education, that is, the objectivity of scientific research papers. The use of first-person pronouns not only does not lose the authoritativeness of the author, but rather adds to its point of view and rationality. Therefore, the author suggest that learners should view the use of first-person pronouns in academic writing dialectically.

Free from the shackles of cultural tradition. The first person pronoun highlights the author's identity in the paper. The native writers are individualistic, so they prefer to use first-person pronouns frequently to express their views. While the Chinese preach a collectivism, many scholars will choose to express their views in more subtle ways and be more modest and cautious. In view of this problem, The teacher could help scholars to change the traditional cultural thinking gradually and express their views with a more direct and clear attitude, so as to achieve the goal of academic exchange.
Enhancing the discourse ability. In the face of the different competence of English between the two groups, teachers should pay attention to enhance the discourse ability in three levels: language, genre and society. (Bhatia, 2008:144) at the language level, Teachers not only need to teach students make words into sentences ,but also need to teach how to maintain cohesion and coherence. In addition, teachers should also train students on how to use appropriate language to express their attitudes, positions and views. At the level of genre, students should be trained to present the research process and results according to the linguistic characteristics of academic papers, and how to express their views properly under the constraints of the corresponding categories. At the social level, teachers should train their students to consider the social distance, the power gap and the intensity of their expression (Hyland, 2005:183) in order to communicate with the readers in an appropriate language strategy to make their arguments more acceptable.

\section{CONCLUSION}

On the basis of the self-compiled corpus, this study explores the frequency of the personal pronoun in order to find the similarities and differences of Chinese L2 learners and Native experts in authorial identities construction in academic writing. The writer find 1. Both Chinese L2 learners and English native experts use the first person pronoun to construct the identity. 2.Chinese L2 learners are more likely to use the first singular form than the Native experts. According to the phenomenon, the writer also find some possible reasons:different model of thinking,various competence of English and diverse academic tradition. Meanwhile, the author provide some pedagogical implications for EAP writing. There are still some limitations in this study: First, the method of Corpus retrieval can be furthered optimized. Second,the results of this study represent only a limited number of disciplines, the question of the identity construction in EAP writing needs to be studied more widely.

\section{REFERENCES}

[1] Alla Zareva. Self-mention and the projection of multiple identity roles in TESOL graduate students presentation: The influence of the written academic genres. English for Specific Purposes 32(2013) 7283

[2] Bucholtz, M\&Hall. K. Identity and Interaction: a Sociocultural Linguistic Approach. Discourse Studies, 2005(7).

[3] Carla,V. Shades of Impersonality:Rhetorical Positioning in the Academic Writing of Italian Students of English. Linguistic and Education,2011,22(2):118-132.

[4] Ken Hyland. Individuality or conformity? Identity in personal and university academic homepages.Computers and Composition 29 (2012) 309-322

[5] Hyland, K. 2002. Authority and invisibility: Authorial identity in academic writing. Journal of Pragmatics, ( 8) : 1091 -1112.

[6] Hyland, K.Directives:Argument and Engagement in Academic Writing.Applied Linguistics, 2002a,23(2):215-239.

[7] Hyland, K.Disciplinary Interactions: Metadiscourse in L2 postgraduate writing. Journal of Second Language Writing,2004,13(2):133-151. 
[8] Hyland,K.(2012). Disciplinary Identities: Individuality and community in academic discourse.Cambridge: Cambridge University Press.

[9] Hyland,K.Genre,discipline and identity.Journal of English for Academic Purposes 19(2015)32-43

[10] Hyland, K. Authority and invisibility I Authorial identity in academic writing . Journal of Pragmatics, 2002, 34: 1091-1112.

[11] Hyland,K.(2015). Academic writing English.Shanghai:Shanghai Foreign Language Education Press.

[12] Ivanic, R. Writing and Identity: The Discoursal Construction of Identity in Academic Writing . Amsterdam: Benjamins, 1998.

[13] Kuo, C - H.(1999).The'I' in identity:Exploring writer identity in students academic writing through the first person pronouns.English for Specific Purposes 18 (Supplement 1):S23-S39.

[14] Murry,R.\&Moore,S.(2006), The Handbook of Academic Writing.A Fresh Approach.New York:Open University Press.

[15] Paltridge, B.,Harbon,L.et al.(2009). Teaching Academic Writing:An Introduction for Teachers of Second Language Writers. Ann Arbor:University of Michigan Press.

[16] Tang, R. \& S. John.(1999).The "I " in identity: Exploring writer identity in student academic writing through the first person pronoun. English for Specific Purposes, 1999, 181 S23.

[17] Tas,E.E.(2008). A Corpus-based Analysis of Genre-specific Discourse of Research:The PhD Thesis and the Research Article in ELT. Anka-ra:Middle East Technical University.

[18] Wong,A.T.Y. Writers' Mental Representations of the Intended Audience and of the Rhetorical Purpose for Writing and the Strategies that They Employed When They Composed. System,2005,33(1):29 